\title{
GOVERNANÇA CORPORATIVA: ANÁLISE DA ADESÃO À LEI 13.303 PELAS EMPRESAS ESTATAIS LISTADAS NA B3
}

\author{
CORPORATE GOVERNANCE: ANALYSIS OF COMPLIANCE WITH \\ LAW 13,303 BY STATE COMPANIES LISTED IN B3
}

\section{GOBIERNO CORPORATIVO: ANÁLISIS DE LA ADHESIÓN A LA LEY 13303 POR EMPRESAS ESTATALES INCLUIDAS EN B3}

\author{
Luís Fernando Gomes de Albuquerque ${ }^{1}$ \\ Sérgio de Iudícibus ${ }^{2}$ \\ Artigo recebido em junho de 2021 \\ Artigo aceito em agosto de 2021
}

\begin{abstract}
RESUMO
A discussão na sociedade sobre o tema transparência é cada vez mais acentuada, tanto no setor público, quanto no privado. As companhias enxergam como uma estratégia de negócio. Baseado nessas informações se buscou dados referentes à adesão à Lei Federal 13.303 que rege sobre o estatuto jurídico das empresas públicas, da sociedade de economia mista e de suas subsidiárias. A pesquisa focou nas empresas públicas listadas na B3, pertencentes aos segmentos ligados a Governança Corporativa, no ano de 2019. O objetivo deste trabalho é apontar a adesão dessas empresas públicas ao artigo $8^{\circ}$ que aborda sobre os requisitos mínimos de transparência. Realizou-se uma pesquisa bibliográfica, em que se buscou o conhecimento de autores renomados no assunto. Também foi realizada pesquisa do tipo descritiva, conduzida por meio de análise documental e uma abordagem quantitativa em amostra de 12 empresas. Levantou-se através do sítio eletrônico disponibilizado pelas empresas as informações pertinentes aos incisos do referido artigo. Realizou-se uma análise buscando a adesão aos incisos do artigo, por empresas e por segmento de governança. O resultado obtido entre os segmentos foi homogêneo. Porém, as informações disponibilizadas pelas companhias não são claras e de difícil acesso.
\end{abstract}

Palavras-chave: Governança Corporativa. Transparência. Empresa Pública.

\section{ABSTRACT}

The discussion in society about the theme of transparency is increasingly accentuaded, both in the public and private sectors. Companies see it as a business strategy. Based on this information, we sought data regarding adherence to Federal Law 13,303, which governs the legal status of public companies, mixed capital companies and their subsidiaries. The research focused on public companies listed in B3, belonging to the Corporate Governance segments, in 2019. The objective of this paper is to point the adhesion of these public companies to article 8 which deals with minimum transparency requirements. A bibliographic research was carried out, where the knowledge of renowned authors on the subject was sought. A descriptive research was also conducted through document analysis and a quantitative approach in a sample of 12 companies. Through the website made available by the

\footnotetext{
${ }^{1}$ Mestre em Ciências Contábeis e Atuariais - PUC-SP. E-mail: luis.fga @icloud.com.

${ }^{2}$ Doutor em Controladoria e Contabilidade pela Universidade de São Paulo. E-mail: siudicibus@osite.com.br.
}

$$
\text { Refas - ISSN 2359-182X v.7, n.6 }
$$


companies, the information pertinent to the items of the referred article was collected. An analysis was performed seeking adherence to the items of the article, by companies and by governance segment. The result obtained between the segments was homogeneous. However, the information provided by companies is not clear and difficult to access.

Keywords: Corporate Governance. Transparency. Public Company.

\section{RESUMEN}

La discusión en la sociedad sobre el tema de la transparencia se acentúa cada vez más, tanto en el sector público como en el privado. Las empresas lo ven como una estrategia empresarial. Con base en esta información, se buscaron datos sobre el cumplimiento de la Ley Federal 13.303 que regula la situación jurídica de las empresas públicas, controladas por el gobierno y sus subsidiarias. La investigación se centró en las empresas públicas cotizadas en B3, pertenecientes a los segmentos vinculados al Gobierno Corporativo, en el año 2019. El objetivo de este trabajo es señalar la adhesión de estas empresas públicas al artículo 8, que aborda los requisitos mínimos de transparencia. . Se realizó una investigación bibliográfica, donde se buscó el conocimiento de autores de renombre sobre el tema. También se realizó una investigación descriptiva, realizada mediante análisis documental y enfoque cuantitativo en una muestra de 12 empresas. La información pertinente a los ítems de dicho artículo fue levantada a través del sitio web puesto a disposición por las empresas. Se realizó un análisis buscando la adherencia a los ítems del artículo, por empresas y por segmento de gobierno. El resultado obtenido entre los segmentos fue homogéneo. Sin embargo, la información proporcionada por las empresas no es clara y de difícil acceso.

Palabras clave: Gobierno Corporativo. Transparencia. Compañía publica.

\section{INTRODUÇÃO}

A sociedade moderna está cada vez mais exigente e mudando sua visão a respeito de políticas públicas, uso dos recursos dos contribuintes, postura dos políticos e consequentemente das empresas públicas. Devido a isso, a palavra transparência vem ganhando notoriedade e está cada vez mais difundida na sociedade. Relacionar informação pública com transparência traz em evidência a palavra corrupção, entendido como corrompimento da fé pelo servidor público, a fim de vantagens individuais. (ROSA et al., 2016).

A Lei 13.303, também conhecida como a Lei das Estatais, traz normas de boas práticas que devem promover segurança, eficiência e melhoria de desempenho. O primeiro ponto dessa lei é a desburocratização dos processos, ganham agilidade nos processos de licitação, contratações diretas e gestão de contratos. Cabe a cada entidade redigir sobre as normas internas.

Posto isso, uma das peças-chave para se combater a corrupção e se realizar uma boa gestão pública no País é a transparência, são conjuntos de práticas que assegurem a informação clara, sucinta e tempestiva para a sociedade. (PLATT NETO; CRUZ; ENSSLIN; ENSSLIN; 2007).

De acordo com o Código das Melhores Práticas de Governança Corporativa do IBGC (2015), a governança estendeu a responsabilidade das empresas e o impacto que elas têm perante a sociedade. Respeito, integridade, transparência são fundamentais para a longevidade das companhias na contemporaneidade. Levando em consideração a adoção das práticas de governança e a responsabilidade com a sociedade, este estudo focou sua pesquisa nas empresas listadas na B3, pertencentes aos segmentos de Governança Corporativa. 
Nesse contexto, surge a pergunta que orienta este estudo: $O$ fato de as empresas estarem listadas num segmento voltado a adoção de práticas de Governança Corporativa, interfere positivamente na adesão das práticas mínimas de transparência da Lei 13.303 redigida no artigo $8^{\circ}$ ? O objetivo da pesquisa é medir se as empresas estatais listadas na B3 pertencentes ao segmento de Governança Corporativa estão seguindo os incisos do artigo $8^{\circ}$ da Lei 13.303.

O interesse para desenvolver esta pesquisa, decorre da crescente visibilidade que o tema transparência ganha nos últimos anos. Este estudo está estruturado em cinco seções, iniciando com essa introdução, num segundo momento é apresentado o referencial teórico com embasamento de autores e pesquisadores sobre o tema. Logo após, a metodologia com os aspectos para o desenvolvimento do estudo, em seguida a análise dos resultados e pôr fím, considerações finais.

\section{REFERENCIAL TEÓRICO}

Inicia-se o referencial teórico pela Governança Corporativa.

\subsection{Governança Corporativa}

Segundo a governança corporativa, as entidades perseguem um propósito e os gestores são os responsáveis para atingir tal propósito. De acordo com Mayer (2012), existem duas linhas de pensamento. A primeira linha é conhecida como primazia dos acionistas, onde busca a maximização da riqueza dos acionistas. Assim, a companhia deve ter um único objetivo, aumentar a riqueza. A segunda linha acredita que a companhia deve ter um propósito mais amplo. Nesse modelo, os administradores devem agir no melhor interesse de longo prazo da companhia, transcendendo o interesse do acionista e comtemplando os demais stakeholders.

Carvalho (2002) define governança corporativa como um mecanismo ou princípio que governa o processo decisório dentro de uma empresa. Já para Tirole (2001), uma boa estrutura de governança é aquela que seleciona os mais hábeis gerentes para defender os interesses dos acionistas.

É histórica a complexidade em gerir organizações. A Governança Corporativa através dos seus princípios, das boas práticas e do apoio do Conselho de Administração, colabora para o estabelecimento de uma adequada gestão (MACHADO JUNIOR e CAMPANÁRIO, 2015, p.101).

As empresas brasileiras de capital aberto são motivadas a adotar as melhores práticas de Governança Corporativa no intuito de perpetuar a empresa.

Possibilitando a transparência com o mercado de capitais, diminuir o custo de capital, edificar a imagem institucional e aumentar o valor da empresa. Os resultados obtidos na pesquisa dos autores refletem que o setor empresarial interpreta a Governança Corporativa como um fator benéfico e desejável 
para as empresas (PONTE et al., 2012 apud MACHADO JUNIOR; PALMISANO; CAMPANÁRIO, 2015, p. 101).

Para o IBGC (2015, p. 20), organização de referência sobre o tema fundada em 1995, governança corporativa é "o sistema pelo qual as sociedades são dirigidas e monitoradas, envolvendo os relacionamentos entre Acionista/Cotista, Conselho de Administração, Diretoria, Auditoria Independente e Conselho Fiscal. As boas práticas de governança corporativa têm a finalidade de aumentar o valor da sociedade, facilitar seu acesso ao capital e contribuir para a sua perenidade".

De acordo com o instituto, a boa governança "assegura aos sócios: equidade, transparência, prestação de contas (accountability) e responsabilidade pelos resultados". Trata-se de uma expansão do conceito de "conflito de agência", tratado pela teoria econômica tradicional. O conflito de agência é a diferença de interesses entre os proprietários e administradores da empresa, que traz à tona a necessidade de controles sobre estes interesses. Governança seria um conceito mais amplo do que meramente o controle. Abrange a "gestão estratégica da empresa e efetiva monitoração da direção executiva" (IBGC, 2015).

Segundo Silveira $(2015$, p. 3), governança corporativa diz respeito à maneira pela qual as sociedades são dirigidas. Incluindo regras que estabelecem o relacionamento dos seus personagens, como: diretoria, acionista e conselho de administração. Possui uma abordagem ampla, englobando áreas como: ética empresarial, gestão, liderança, finanças, direito, economia, contabilidade, psicologia e outras. Resumindo, visa a criar na empresa um ambiente onde as pessoas respeitem as regras impostas e possam tomar decisões no melhor interesse da organização. Para Valente (2018, p. 1), a governança corporativa estabelece dentro de uma organização, uma estrutura onde os gestores tomarão decisões e direcionarão o caminho da empresa respeitando as normas e regras da empresa.

\footnotetext{
Encarregada de assegurar que a organização cumpra sua missão de modo eficaz e também que atenda às necessidades dos que a controlam ou que detêm poder sobre ela (como seus proprietários, órgãos governamentais, sindicatos e empregados, grupos de pressão) (MINTZBERG, 2003, p.24).
}

Há diversas teorias e pensamentos que explicam como as companhias devem ser governadas. Porém, um bom sistema de governança depende da combinação de todas. A teoria da representação, ou agency theory, desenvolvida por Jensen e Meckling, é a mais abordada para os estudos da governança corporativa. Visa explicar como ocorre o desalinhamento entre executivos e acionistas. Os executivos, ou agents, são os representantes, os que tomam a decisão do negócio. Os acionistas, ou principals, "são os representados, transferem seu poder de decisão para os executivos" (SILVEIRA, 2015, p. 34).

No mundo dos negócios, o conflito de agência dificilmente será evitado. Vivemos uma época onde a descontinuidade e a incerteza prevalece. Transformações em comportamentos sociais, econômicas e tecnológicas. Diante das incertezas vivenciadas no mundo dos negócios, "a gestão precisa se adaptar ao dinamismo e a velocidade da transformação" (ROSSETTI; ANDRADE, 2016, p. 86).

A inexistência do agente perfeito é um dos motivos para a existência do conflito de agência. Jensen e Meckling acreditam que a natureza humana conduz os indivíduos a 
maximizar os seus próprios objetivos, dificilmente objetivos alheios movem pessoas a serem eficazes.

\subsection{Governança Pública}

Para Dias e Cario (2014), a governança pública é algo o mais do que um artifício para administração pública. É uma relação entre agentes públicos e privados no processo de políticas públicas, um movimento de reforma da gestão pública.

Lynn e Malinowska (2018) definem governança pública como um estudo entre disciplinas centradas na relação: governo, sociedade e mercado. Todos participando dentro de um mesmo contexto de transformação e capazes de agirem efetivamente.

Por fim, Pedersen e Johannsen (2018), enfatiza que serviços públicos mais eficientes e resultados positivos podem ser alcançados por meio de processos administrativos flexíveis.

O conceito de eficiência está relacionado à combinação ótima entre recursos e produtos, ou seja, a eficiência objetiva maximizar a produção minimizando os recursos aplicados. Nesse contexto, a eficiência está relacionada aos meios para alcançar o objetivo e não apenas ao objetivo propriamente dito (PEÑA, 2008).

A eficiência no setor público vem ganhando destaque. Discute-se que a eficiência no setor público pode estar associada à otimização da aplicação de recursos, possibilitando a ampliação da qualidade dos serviços prestados à população (STASTNA; GREGOR, 2011). Além disso, sugere-se que a eficiência no setor público é um fator que pode contribuir para alcançar melhor desempenho socioeconômico (ADAM; DELIS; KAMMAS, 2011).

No setor público a exigência de prestar contas é diferente das instituições privadas. A organização pública que está comprometida em assegurar a integridade do trabalho tomará as medidas cabíveis para evitar o aparecimento do comportamento não ético. Podemos concluir que a governança está diretamente ligada em manter a transparência nos gastos e nas contas públicas, accountability. (HEADLEY et al, 2014).

Após exposto isso, as empresas estatais estão obrigadas a atender o disposto na Lei 13.303, também conhecida como a Lei das Estatais. Essa lei incorporou boas práticas de governança corporativa, para promover a segurança, eficiência e melhoria de desempenho. As estatais ganharam agilidade e desburocratização em seus processos, como: contratações diretas, gestão de contratos e agilidade no processo de licitação. Cabendo a ela a redigir suas próprias normas, de acordo com sua atuação e estrutura.

\section{MÉTODO}

Para esta pesquisa foi adotado o método bibliográfico. Consultaram-se obras de autores referenciais no assunto, artigos, revistas, jornais e sites corporativos. Segundo Martins e Theóphilo (2016), a pesquisa bibliográfica é um excelente meio de pesquisa, pois visa a base para a construção da teoria, é necessária para a condução de qualquer pesquisa científica.

Com o intuito de atender o objetivo deste estudo, foi realizada uma pesquisa descritiva conduzida por meio de análise documental e abordagem quantitativa. Uma pesquisa 
quantitativa é aquela onde os dados e evidências coletadas podem ser quantificadas, mensurados. (MARTINS; THEÓPHILO, 2016).

A população do estudo compõe-se do conjunto de companhias abertas da B3, listadas no segmento de Governança Corporativa.

Em um primeiro momento levantamos as empresas listadas na B3, pertencentes aos segmentos de governança Nível 1, Nível 2 e Novo Mercado, totalizando uma amostra de 12 empresas. Buscaram-se dados através do sítio eletrônico de cada companhia sobre a adesão aos incisos do art. $8^{\circ}$ da Lei 13.303. A adesão foi analisada por incisos, por empresas e segmentos de governança.

Os dados levantados foram planilhados e organizados de forma que ficasse claro e objetivo para a pesquisa. Realizou-se uma análise geral das empresas e aplicado a sigla " $\mathrm{S}$ " no caso de adesão ao inciso ou a sigla " $\mathrm{N}$ " no caso de não adesão ou de não encontrar a informação buscada.

\section{RESULTADOS E DISCUSSÃO}

O tópico contém a descrição e análise de dados coletados. Apresenta-se primeiramente a estatística descritiva dos números e do percentual de adesão das empresas à Lei 13.303 de 2016, que trata do estatuto jurídico da empresa pública, da sociedade de economia mista e de suas subsidiárias, também conhecido como Lei das Estatais. A análise dos dados levantados para esta pesquisa tem como foco o artigo oitavo, que discorre sobre os requisitos de transparência que as empresas públicas e subsidiárias devem seguir. A Tabela 1 descreve as empresas pesquisadas, que estão listadas na B3 e pertencem ao segmento de Governança Corporativa.

Tabela 1 - Empresas Pesquisadas

\begin{tabular}{ccc}
\hline Empresa & Segmento & Setor \\
\hline Banrisul & Nível 1 & Financeiro \\
Cia Estadual de Distribuição de Energia Elétrica - CEEE & Nível 1 & Energia Elétrica \\
Cia Energética de Minas Gerais - CEMIG & Nível 1 & Energia Elétrica \\
Cia Paranaense de Energia - COPEL & Nível 1 & Energia Elétrica \\
Centrais Elétrica Brasileira S/A - Eletrobrás & Nível 1 & Energia Elétrica \\
Centrais Elétricas de Santa Catarina - CELESC & Nível 2 & Energia Elétrica \\
Petróleo Brasileiro S/A - Petrobrás & Nível 2 & Petróleo \\
Cia Saneamento do Paraná - SANEPAR & Nível 2 & Água e Saneamento \\
BB Seguridade Participações S/A & Novo Mercado & Previdência e Seguros \\
Banco do Brasil & Novo Mercado & Financeiro \\
Cia Saneamento de Minas Gerais - COPASA & Novo Mercado & Água e Saneamento \\
Cia Saneamento Básico do Estado de São Paulo - SABESP & Novo Mercado & Água e Saneamento \\
\hline
\end{tabular}

Fonte: B3 (2019). Elaborado pelos autores. 
Foi analisada uma amostra de doze empresas públicas, pertencentes a cinco setores distintos e listados em três segmentos diferentes. O setor com maior representação na amostra foi o de Energia Elétrica, com $42 \%$ da amostra; em seguida o setor de Água e Saneamento com 25\%; em terceiro lugar o setor Financeiro com $17 \%$ e por último os setores de Petróleo e Previdência com $8 \%$ de representatividade cada um.

A Lei 13.303 tem como um dos objetivos promover a segurança, eficiência e melhoria no desempenho. Segundo o Art. $8^{\circ}$ As empresas públicas e as sociedades de economia mista deverão observar, no mínimo, os seguintes requisitos de transparência:

I - elaboração de carta anual, subscrita pelos membros do Conselho de Administração, com a explicitação dos compromissos de consecução de objetivos de políticas públicas pela empresa pública, pela sociedade de economia mista e por suas subsidiárias, em atendimento ao interesse coletivo ou ao imperativo de segurança nacional que justificou a autorização para suas respectivas criações, com definição clara dos recursos a serem empregados para esse fim, bem como dos impactos econômicofinanceiro da consecução desses objetivos, mensuráveis por meio de indicadores objetivos;

II - adequação de seu estatuto social à autorização legislativa de sua criação;

III - divulgação tempestiva e atualizada de informações relevantes, em especial a relativas a atividades desenvolvidas, estrutura de controle, fatores de risco, dados econômico-financeiros, comentários dos administradores sobre o desempenho, políticas e práticas de governança corporativa e descrição da composição e da remuneração da administração;

IV - elaboração e divulgação de política de divulgação de informações, em conformidade com a legislação em vigor e com as melhores práticas;

V - elaboração de política de distribuição de dividendos, à luz do interesse público que justificou a criação da empresa pública ou da sociedade de economia mista;

VI - divulgação, em nota explicativa às demonstrações financeiras, dos dados operacionais e financeiros das atividades relacionadas à consecução dos fins de interesse coletivo ou de segurança nacional;

VII - elaboração e divulgação da política de transações com partes relacionadas, em conformidade com os requisitos de competitividade, conformidade, transparência, equidade e comutatividade, que deverá ser revista, no mínimo, anualmente e aprovada pelo Conselho de Administração;

VIII - ampla divulgação, ao público em geral, de carta anual de governança corporativa, que consolide em um único documento escrito, em linguagem clara e direta, as informações que trata o inciso III;

IX - divulgação anual de relatório integrado ou de sustentabilidade.

A Tabela 2 mostra os dados levantados na pesquisa, onde a letra "S" significa que a empresa adere o inciso do artigo $8^{\circ}$ da Lei 13.303 e a letra "N" significa que a empresa não adere o inciso ou adere parcialmente. 
Tabela 2 - Adesão das empresas aos requisitos de transparência

\begin{tabular}{|c|c|c|c|c|c|c|c|c|c|c|c|c|}
\hline Empresas & $\begin{array}{l}\mathscr{D} \\
\stackrel{\Xi}{\Xi} \\
\stackrel{\mathscr{W}}{\Xi}\end{array}$ & $\begin{array}{l}\Omega \\
\frac{M}{M} \\
\frac{M}{M}\end{array}$ & 愛 & 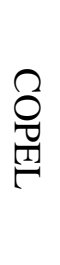 & 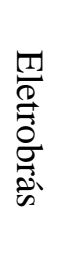 & 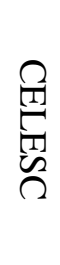 & 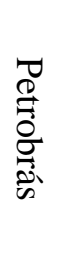 & 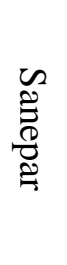 & 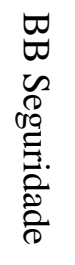 & $\underset{\varpi}{\varpi}$ & $\begin{array}{l}0 \\
0 \\
D \\
D \\
D\end{array}$ & $\begin{array}{l}\infty \\
\mathbb{D} \\
\mathbb{1} \\
\tilde{D}\end{array}$ \\
\hline $\begin{array}{l}\text { I - Elaboração de carta anual } \\
\text { subscrita pelo Conselho de } \\
\text { Administração. }\end{array}$ & $\mathrm{N}$ & $\mathrm{N}$ & $\mathrm{N}$ & $\mathrm{N}$ & $\mathrm{S}$ & $\mathrm{N}$ & $\mathrm{S}$ & $\mathrm{N}$ & $\mathrm{N}$ & $\mathrm{S}$ & $\mathrm{S}$ & $\mathrm{S}$ \\
\hline $\begin{array}{c}\text { II - Adequação do Estatuto Social } \\
\text { à autorização legislativa de sua } \\
\text { criação. }\end{array}$ & $\mathrm{S}$ & $\mathrm{N}$ & $\mathrm{S}$ & S & $\mathrm{N}$ & $\mathrm{S}$ & $\mathrm{S}$ & $S$ & S & $\mathrm{S}$ & $\mathrm{S}$ & $\mathrm{N}$ \\
\hline $\begin{array}{l}\text { III - Divulgação tempestiva e } \\
\text { atualizada de informações. }\end{array}$ & $\mathrm{S}$ & $\mathrm{S}$ & $\mathrm{S}$ & $\mathrm{S}$ & $\mathrm{S}$ & $S$ & $\mathrm{~S}$ & $\mathrm{~S}$ & $\mathrm{~S}$ & $\mathrm{~S}$ & $\mathrm{~S}$ & $S$ \\
\hline $\begin{array}{l}\text { IV - Política de divulgação de } \\
\text { informações. }\end{array}$ & $\mathrm{S}$ & $S$ & $\mathrm{~S}$ & $S$ & $S$ & $\mathrm{~S}$ & $S$ & $S$ & S & $\mathrm{S}$ & $S$ & $\mathrm{~S}$ \\
\hline $\begin{array}{l}\text { V - Elaboração de políticas de } \\
\text { distribuição de dividendos. }\end{array}$ & $S$ & $\mathrm{~S}$ & $\mathrm{~S}$ & $\mathrm{~S}$ & $\mathrm{~S}$ & $S$ & S & $\mathrm{S}$ & $S$ & $\mathrm{~N}$ & $\mathrm{~S}$ & $\mathrm{~S}$ \\
\hline $\begin{array}{l}\text { VI - Divulgação em notas } \\
\text { explicativas às demonstrações } \\
\text { financeiras. }\end{array}$ & $\mathrm{S}$ & $\mathrm{S}$ & $\mathrm{S}$ & $S$ & $S$ & $S$ & $\mathrm{~S}$ & $S$ & S & $\mathrm{S}$ & $\mathrm{S}$ & $\mathrm{S}$ \\
\hline $\begin{array}{l}\text { VII - Elaboração e divulgação da } \\
\text { política de transações com partes } \\
\text { relacionadas. }\end{array}$ & $\mathrm{N}$ & S & $\mathrm{S}$ & $S$ & $\mathrm{~S}$ & $\mathrm{~S}$ & $\mathrm{~N}$ & $S$ & $\mathrm{~S}$ & $\mathrm{~S}$ & $\mathrm{~N}$ & $\mathrm{~S}$ \\
\hline $\begin{array}{l}\text { VIII - ampla divulgação de carta } \\
\text { anual de GC, que consolide em } \\
\text { único documento, informações do } \\
\text { inciso III. }\end{array}$ & $\mathrm{N}$ & $\mathrm{N}$ & $\mathrm{N}$ & $S$ & $S$ & $\mathrm{~N}$ & $S$ & $S$ & $\mathrm{~S}$ & $S$ & $\mathrm{~S}$ & $S$ \\
\hline $\begin{array}{l}\text { IX - divulgação anual de relatório } \\
\text { integrado ou de sustentabilidade. }\end{array}$ & $\mathrm{N}$ & S & S & $S$ & $S$ & $S$ & S & S & $\mathrm{S}$ & S & $\mathrm{S}$ & $\mathrm{S}$ \\
\hline
\end{tabular}

Fonte: B3 (2019). Elaborado pelos autores.

A Tabela 2 aponta a adesão pelas empresas por incisos no artigo $8^{\circ}$.

O inciso I aborda a elaboração de carta anual pelos membros do Conselho de Administração onde afirmam o compromisso de executar os objetivos públicos da empresa pública em atendimento ao interesse coletivo. Numa amostra de 12 empresas, identificou-se que sete empresas, ou 58\%, aderem integralmente a este inciso e cinco empresas, ou $42 \%$ não aderem, o setor de energia foi o setor que menos aderiu ao inciso I.

Analisando o inciso II, que trata da adequação do estatuto social à autorização legislativa de sua criação, verificou-se que três empresas das 12 estudadas não obtiveram 
avaliação nesse quesito, pois não disponibilizaram acesso ao estatuto social. As demais disponibilizaram o documento e ele está de acordo com o inciso estudado.

O inciso III explica a divulgação de informações sobre riscos, estrutura de controle, informações econômicas, políticas e práticas de governança corporativa em tempo oportuno para os interessados. Todas as 12 empresas aderiram a este inciso.

Verificando o inciso IV, que trata da política de divulgação de informações, verificouse que todas as empresas aderiram adequadamente ao mesmo.

$\mathrm{O}$ inciso $\mathrm{V}$ indica a política de distribuição de dividendos, da amostra estudada de 12 empresas, 11 empresas, ou 92\% aderiram ao inciso, uma única empresa não divulgou sua política de distribuição de dividendos, impossibilitando a verificação de existência de uma política clara que aponto o inciso $\mathrm{V}$.

O inciso VI trata da divulgação, em nota explicativa das demonstrações financeiras, divulgação dos dados operacionais e financeiros das atividades relacionadas a execução dos fins de interesse coletivo ou de segurança nacional. Todas as 12 empresas estudadas aderiram ao inciso VI.

No inciso VII é abordada a divulgação da política de transações com partes relacionadas, onde seguem requisitos de transparência, conformidade, equidade e que deve ser revisto anualmente pelo Conselho de Administração. No estudo deste inciso, nove empresas aderiram ao inciso, enquanto três empresas não aderiram.

O inciso VIII trata da divulgação, ao público em geral, de carta anual de governança corporativa, que consolide em um documento informações do inciso III. Da amostra pesquisada, oito empresas aderiram a este inciso, enquanto quatro empresas não aderiram ao inciso VIII.

O inciso IX, último inciso do artigo $8^{\circ}$, aborda sobre a divulgação anual de relatório ou de sustentabilidade. Apenas uma empresa do setor financeiro não disponibilizou o relatório de sustentabilidade, as demais disponibilizaram e com fácil acesso. Este relatório é um documento que várias empresas utilizam para divulgar suas informações de maneira transparente e concisa.

A Tabela 3 mostra uma variação percentual de adesão ao artigo $8^{\circ}$ da Lei 13.303. Todas as empresas estão com o índice acima de 50\%, algumas chegando a quase $100 \%$ de adesão. Empresas do setor de Água e Saneamento são as que mais aderiram aos incisos, cada empresa das três que representam o setor ficou sem aderir apenas a um inciso. Sanepar não aderiu ao inciso I, elaboração de carta anual pelo Conselho. COPASA deixou de aderir ao inciso VII que fala sobre a política de elaboração e divulgação de transações com partes relacionadas e a SABESP não disponibilizou o acesso ao seu estatuto social, que é tratado pelo inciso II. O banco Banrisul é a empresa estatal que menos aderiu aos incisos estudados. Não aderiu ao inciso I, sobre a carta anual emitida pelo Conselho de Administração; ao inciso VII, sobre a política de transações com partes relacionadas; inciso VIII, sobre a divulgação anual de carta da Governança Corporativa e ao inciso IX, divulgação anual de relatório integrado ou de sustentabilidade. 
Tabela 3 - Variação em adesão aos incisos

\begin{tabular}{ccc}
\hline EMPRESA & $\mathbf{N}$ & $\mathbf{S}$ \\
\hline Banrisul & $44 \%$ & $56 \%$ \\
CEEE & $33 \%$ & $67 \%$ \\
CEMIG & $22 \%$ & $78 \%$ \\
COPEL & $11 \%$ & $89 \%$ \\
Eletrobrás & $11 \%$ & $89 \%$ \\
CELESC & $22 \%$ & $78 \%$ \\
Petrobrás & $11 \%$ & $89 \%$ \\
Sanepar & $11 \%$ & $89 \%$ \\
BB Seguridade & $11 \%$ & $89 \%$ \\
BB & $11 \%$ & $89 \%$ \\
COPASA & $11 \%$ & $89 \%$ \\
SABESP & $11 \%$ & $89 \%$ \\
\hline
\end{tabular}

Fonte: B3 (2019). Elaborado pelos autores.

Todas as empresas do segmento de Novo Mercado atingiram $89 \%$ de adesão ao artigo $8^{\circ}$ da Lei 13.303. As empresas do Nível 2 de Governança Corporativa obtiveram o seguinte resultado: CELESC - 78\%; Petrobrás - 89\%; e SANEPAR - 89\%. As empresas do Nível 1 do segmento de Governança Corporativa: Banrisul, CEEE e CEMIG tiveram no máximo 78\% de adesão, COPEL e Eletrobrás alcançaram 89\%. As empresas estatais obtiveram um resultado adequado, mostraram que estão trabalhando para chegar aos $100 \%$ de adesão ao artigo $8^{\circ}$, que trata sobre os requisitos mínimos de transparência.

\section{CONSIDERAÇÕES FINAIS}

O objetivo do estudo foi identificar a adesão aos incisos do artigo. $8^{\circ}$ referente a Lei 13.303, pelas empresas estatais, listadas na B3 pertencentes aos segmentos de Governança Corporativa: Nível 1, Nível 2 e Novo Mercado. O pesquisador escolheu este segmento, por entender que empresas que seguem o mais alto padrão de governança, tendem a ser mais transparentes e claras no trato de suas informações. O objetivo do estudo foi alcançado, as informações levantadas corroboraram para tal.

Neste estudo realizou-se uma pesquisa descritiva, conduzida por meio de análise documental e abordagem quantitativa. Os resultados mostraram que as empresas estão aderindo aos incisos do artigo $8^{\circ}$. Do total da amostra de 12 empresas, oito companhias atingiram 89\% de adesão; duas empresas atingiram 78\% de adesão; uma empresa com 67\% e uma empresa com 56\%. O setor de Água e Saneamento foi o único em que todas as empresas envolvidas atingiram $89 \%$ de adesão. Apesar de a adesão ser algo representativo, identificouse uma limitação à pesquisa, existe uma dificuldade de encontrar as informações nos sítios 
eletrônicos. As companhias não disponibilizam as informações de modo claro e transparente, dificultando a compreensão dos interessados.

Respondendo a questão desta pesquisa: $\mathrm{O}$ fato de as empresas estarem listadas num segmento voltado à adoção de práticas de Governança Corporativa, interfere positivamente na adesão das práticas mínimas de transparência da Lei 13.303 redigida no artigo $8^{\circ}$ ? Ficou evidente que interfere positivamente, pois $67 \%$ da amostra estudada atingiram $89 \%$ de adesão ao art. $8^{\circ}$, ou seja, ficando apenas um inciso sem ter o objetivo atendido.

A pesquisa contribuiu para evidenciar a transparência adotada pelas empresas estatais em expor seus objetivos, riscos, números econômicos e financeiros aos stakeholders envolvidos. Evidenciou também as dificuldades em encontrar informações claras e objetivas, um ponto onde as empresas pesquisadas podem estar considerando.

Entende-se que após esta pesquisa, novos estudos podem ser realizados. Pode-se aprofundar esta mesma metodologia comparando empresas estatais do segmento de governança aos demais segmentos. Outra linha de metodologia adotada é uma pesquisa aprofundada na Lei 13.303 e adesão pelas companhias estatais.

\section{REFERÊNCIAS}

ADAM, A.; DELIS, M.; KAMMAS, P. (2011). Public sector efficiency: leveling the playing field between OECD countries. Public Choice, 146(1), 163-183.

CARVAlHO, A. G. Governança Corporativa no Brasil em perspectiva. Revista de Administração. v. 37, n. 3, 2002, p. 19-32.

DIAS, T.; CARIO, S. A. F. Governança pública: ensaiando uma concepção: Contabilidade, Gestão e Governança, 17(3), 89-108.

HEADLEY, S.S.; RAITER, J.R.; LIMA, R.J.B.; DALLABONA, S.H. Administração Pública. Londrina: Editora e Distribuidora Educacional, 2014

IBGC - INSTITUTO BRASILEIRO DE GOVERNANÇA CORPORATIVA. Código das melhores práticas de governança corporativa. 5a ed. São Paulo, 2015.

LYNN, L. E. Jr.; MALINOWSKA, A. (2018). How are patterns of public governance changing in the US and the EU? It's complicated.Journal of Comparative Policy Analysis: Research and Practice, 20(1), 36-55.

MACHADO JUNIOR, C.; PALMISANO, A.; MAZZALI, L. CAMPANÁRIO, M. A. O conhecimento em Governança Corporativa. Santa Catarina, v. 12, n. 26, p. 99-118, 2015.

MARTINS, G. de A.; THEÓPHILO, C. R. Metodologia da Investigação Científica: para Ciências Sociais Aplicadas. 3a. ed. São Paulo: Atlas, 2016.

MAYER, C. Firm Commitment. Oxford University Press, 2012.

MINTZBERG, H. Criando Organizações Eficazes. 2a. ed. São Paulo: Atlas, 2003.

PEDERSEN, K. H., \& Johannsen, L. (2018). New public governance in the Baltic States: flexible administration and rule bending.Public Performance \& Management Review, 41(3), 648-667.

PEÑA, C. R. (2008). Um modelo de avaliação da eficiência da administração pública através do método análise envoltória de dados (DEA). Revista de Administração Contemporânea, 12(1), 83-106.

PLATT NETO, O. A.; CRUZ, F. da; ENSSLIN, S. R.; ENSSLIN, L. Publicidade e transparência das contas públicas: obrigatoriedade e abrangência desses princípios na Administração Pública brasileira. Contabilidade Vista \& Revista, Belo Horizonte, MG, v. 
18, n.1, p. 75-94, jan./mar. 2007. Disponível em: https://revistas.face.ufmg.br/ index.php/contabilidadevistaerevista/article/view/320/313. Acesso em: 05 set. 2019.

ROSA, M. M. da; BERNARDO, F. D.; VICENTE, E. F. R.; PETRI, S. M. A Lei de Acesso à Informação como instrumento de controle social: diagnóstico dos municípios do Sul do Brasil à luz do artigo $8^{\circ}$ da Lei 12527/2011. Navus, Florianópolis, SC, v. 6, n. 1, p. 72-87, jan./mar. 2016. DOI: https://doi.org/10.22279/navus.2016.v6n1.p72-87.359.

ROSSETTI, J. P.; ANDRADE, A. Governança Corporativa: fundamentos, desenvolvimento e tendências. 7a. ed. São Paulo: Atlas, 2016.

SILVEIRA, A. D. M. da. Governança Corporativa: no Brasil e no Mundo. 2a. ed. Rio de Janeiro: Elsiever, 2015.

STASTNA, L.; GREGOR, M. (2011). Local government efficiency: evidence from the Czech municipalities (IES Working Paper No. 14/2011). Prague, Czech Republic: Charles University.

TIROLE, J. Corporate Governance. Econometrica, v.69, n. 1, 2001, pp. 1-35.

VALENTE, P. G. Governança Corporativa: guia do conselheiro para empresas familiares ou fechadas. Rio de Janeiro: Alta Books, 2018. 